\title{
Educational Technology for “Operating System” Course Based on KM Teaching Method
}

\author{
Xiong Luo, Chengyao Wang, and Yi Chen \\ School of Computer and Communication Engineering \\ University of Science and Technology Beijing (USTB) \\ 30 Xueyuan Road, Haidian District, Beijing 100083, China \\ e-mail:xluo@ustb.edu.cn
}

\begin{abstract}
In this paper, we propose a novel educational technology based on the KM teaching method considering the organization of the teaching content and the problems appeared in the teaching of "Operating System" course. With the help of this educational technology, the implementation of our teaching model is based on underlying logic of mind process, and it includes several key processing steps, i.e., extracting knowledge point, linking and netting, expanding, modeling, and embedding knowledge. Finally, under this teaching mode, it will provide overall intellectual framework and logic diagram of knowledge elements, through micro structure and macro formation to firmly grasp knowledge. This model makes the abstract knowledge of operation system figurative. And eventually the course can be taught in accord with the logical thinking.
\end{abstract}

Keywords-operating system; KM teaching method; educational technology.

\section{INTRODUCTION}

Operating system is an important system software in the computer. The "Operating System" course is a basic course of some majors, such as Computer Science and Electronic Information Engineering. This undergraduate course mainly teaches the basic concepts and principles of the operating system, such as process management, memory management, storage management, and so on. Through the learning, the students are able to understand the basic knowledge of design and implementation for an computer operating system, including the concepts of the operating system, data structures, and algorithms. The course lays the solid foundation for the further learning of advanced operating system.

The "Operating System" course is theoretical and abstract. The course requires students to have a foundation of specialized core courses. As a result, it is hard for teachers to teach and for students to understand. Moreover, with the rapid development of the computer technology and operating system, the operating system software becomes more and more complex, which brings challenges to innovation of the teaching model of "Operating System" course. Although there are some effectual teaching methods [1-4]. However, these methods do not solve the problem as a whole from the view of the system.

Considering the characteristics of "Operating System" course, in this paper, we propose a novel educational technology by combining with $\mathrm{KM}$ teaching method to enhance students' learning interest and efficiency.

\section{PRESENT SituAtion OF TEACHING}

The main characteristics of "Operating System" course are fast-update and abstract. These become the difficult points of the teaching. The representative problems of the teaching are as listed below.

\section{A. Difficulty in Mastering Knowledge System}

For an interdisciplinary course, the students cannot have an overall concept of the knowledge without the in-depth analysis of the operating system.

\section{B. Lack of Learning Initiative}

By means of the traditional teaching method, the students get bored by the course and lose interest in their learning motivation.

\section{Delay in the Knowledge Update}

Because of the limitation of teaching calendar, the teachers sometimes only introduce the basic concepts of the operating system and rarely present the latest technologies and applications in current development of the operating system.

All the problems mentioned above, in the final analysis, are that how to form the knowledge system faster and better, and then expand the deep level knowledge.

\section{KM TEACHING METHOD}

$\mathrm{KM}$ teaching method was proposed to implement the teaching by integrating the knowledge logic structure and mind mapping through the long-term teaching practice [5]. KM teaching method is a synthetic application which combines information processing theory, cognitive psychology, structuralism methodology, and so on many disciplines. It reveals the cognitive mechanism in the process of teaching at various levels. At present, KM teaching method has been applied to some special courses of computer science, i.e., discrete mathematics, data structure, computer network, software engineering, etc [6].

Knowledge logical structure is the core idea of $\mathrm{KM}$ teaching method, which is constructed by profiling the theoretical structure of the teaching content. Fig. 1 is a schematic diagram of KM teaching scheme. 


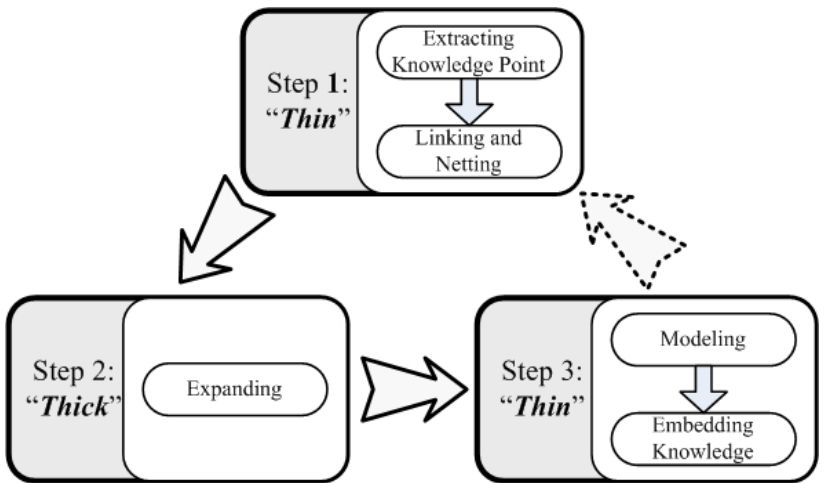

Figure 1. Schematic diagram for implementation of KM teaching method.

In general, the teaching content is organized by following three steps, i.e., “Thin”, “Thick”, and "Thin”. Practically speaking, as shown in Fig. 1, three step are also decomposed into a sum of processing steps, i.e., extracting knowledge point, linking and netting, expanding, modeling, and embedding knowledge. And the compact intellectual framework is formed. Then knowledge logical structure integrates with mind mapping through micro formation to develop a fusion mechanism. In KM teaching method, teaching content is summarized in the form of graphs and charts. The students can have an comprehensive understanding of the knowledge by virtue of graphs and charts which make knowledge clear and easy to remember. While teaching, teachers should explain the basic framework of the teaching content and introduce the main content. Students can learn secondary content by themselves, which mobilizes their learning subjective initiative and enthusiasm.

\section{TEACHING PRACTICE BASED ON THE KM TEACHING METHOD}

\section{A. Design Process of "Operating System" Course}

According to "Operating System” teaching material [7] and the KM teaching method, the design process of the novel educational technology is shown below
We analyze every chapter of "Operation System" course, and extract the main content from every chapter. Regardless of the minor content, we establish a basic framework of the course. For "Operation System" course, the knowledge points are as follows:

- Chapter 1: Introduction to operating system. It includes the concept and development of operating system.

- Chapter 2: Process Management. It includes processes concept, processes scheduling, operations on processes, multithreading models, thread libraries and threading issues, CPU scheduling algorithms, thread scheduling, multiple-processor scheduling, semaphores, classic problems of process synchronization, monitors, deadlock characterization, deadlocks and starvation.

- Chapter 3: Memory Management. It includes swapping, contiguous memory allocation, paging, segmentation, virtual memory concept, copy-on-write, page replacement, allocation of Frames, memory-mapped files, allocating kernel memory.

- Chapter 4: Storage Management. It includes file access methods, directory and disk structure, file-system mounting and implementation, allocation methods, free-space management, disk structure and scheduling, disk management, swap-space management, RAID structure, application I/O Interface, transforming $\mathrm{I} / \mathrm{O}$ requests to hardware operations, and STREAMS.

- Chapter 5: Introduction to one popular operating system, i.e., Linux. It includes design principles and implementation of Linux.

2) Linking-Netting-Expanding-Modeling-Embedding

We form the knowledge networks considering the horizontal and vertical direction of the knowledge points. We implement the processing framework of Fig. 1 by using the approach of linking-netting-expanding-modeling-embedding.

\section{1) Extracting Knowledge Point}

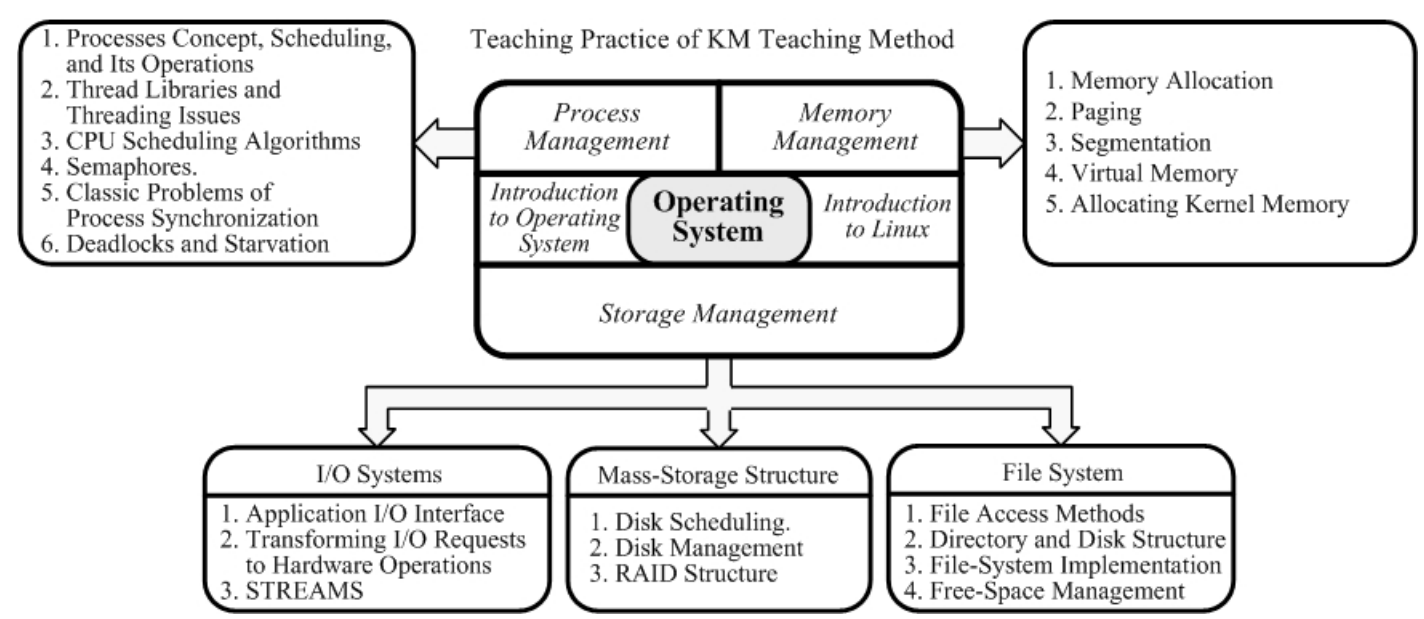

Figure 2. Logical structure of "Operating System” course. 
This method refines the teaching content. After students understand the knowledge framework, they can go back to have an intensive reading of the knowledge. Finally they will develop their own knowledge by assimilation and absorption of the knowledge. Intrinsically this is the dynamic process of the understanding in a spiral.

\section{B. Logical Structure of "Operating System"}

After completing the above processing steps, the top logical structure of "Operating System" course is described as Fig. 2. Moreover, on the basic structure, the KM teaching method can also be implemented in every chapter of "Operating System” teaching material to form the sub-graph of the logical structure.

\section{CONCLUSION}

With the help of knowledge logical structure in KM teaching method, students can master the knowledge framework of the course. And then students fill the details of the knowledge in this structure. On one hand, students can grasp the main clue fast and understand knowledge easily by means of this novel educational technology. On the other hand, teachers can use knowledge logical structure to implement corresponding teaching arrangement according to students' personality, which will improve the quality of teaching effectively.

\section{ACKNOWLEDGMENT}

This work was jointly supported by the Project of National Characteristic Major Construction of Computer Science and Technology under Grant TS1Z007 and the Project of Beijing Characteristic Major Construction of Computer Science and Technology under Grant 20083.

\section{REFERENCES}

[1] Q. Wu and L. Cao, "Teaching mode of operating system course for undergraduates majoring in computer sciences," in Proc. Int. Conf. Comput. Sci. Educ., Nanning, China, July 2009, pp. 1412-1415.

[2] H. Li, C. Yin, Y. Xu, and Q. Guo, "Construction of the practical teaching system on operating systems course," in Proc. Int. Workshop Educ. Technol. Comput. Sci., Wuhan, China, March 2010, pp. 405-408.

[3] X. Yang and C. Shan, "The design of teaching system of the public elective course "operations research"," Lect. Notes Electr. Eng., vol. 112 LNEE, pp. 207-211, 2011.

[4] L. He, G. Gu, and B. Chen, "Study on teaching method of project in the operating system," Adv. Mater. Res., vol. 605-607, pp. 2579-2582, 2013.

[5] B. Yang, N. Ma, and H. Bao, "Research on cognitive-based KLSKT teaching view and KM teaching theory," Adv. Intell. Soft Comput., vol. 116 AISC, no. 1, pp. 387-393, 2012.

[6] X. Ju and J. Chen, "Research of software engineering teaching based on KM pedagogy," Comput. Educ., no. 20, pp. 107-110, October 2010. (in Chinese)

[7] A. Silberschatz, P. B. Galvin, and G. Gagne, Operating Systems Concepts, 8th ed. Hoboken, New Jersey, John Wiley \& Sons, 2008. 